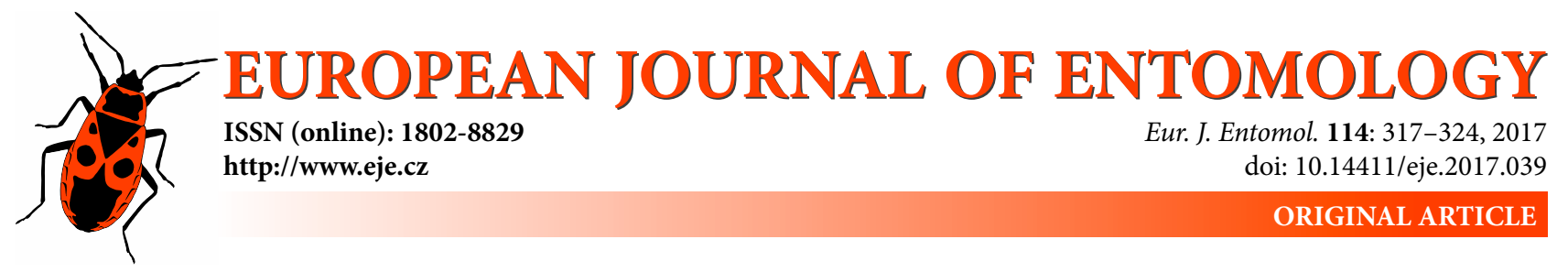

\title{
Not simply red: Colouration of red wood ant Formica rufa (Hymenoptera: Formicidae) is polymorphic, modular and size-dependent
}

\author{
OKSANA SKALDINA and JounI SORVARI \\ Department of Environmental and Biological Sciences, University of Eastern Finland, P.O. Box 1627, FI-70211 Kuopio, Finland; \\ e-mails: oksana.skaldina@uef.fi, jouni.sorvari@uef.fi
}

Key words. Hymenoptera, Formicidae, colouration variability, melanization, modularity, pigment patterns, polymorphism, wood ants

\begin{abstract}
Insects produce pigment and structural colours mainly for camouflage, signaling, physical protection or temperature regulation, and colour patterns can provide information about individual quality. Although the evolutionary function and nature of the variability in colouration are well known for many invertebrate taxa, there is little information on this topic for ants. We studied individual variation in the melanin-based colour traits of workers of the red wood ant, Formica rufa (Hymenoptera: Formicidae), from 20 colonies in Southern Finland and revealed the type of colouration in this species. First, using the threshold approach we distinguished between continuous and discrete variations. Furthermore, the analyses affirmed nine discrete morphs in terms of the colouration on the head and eight on the pronotum, while only continuous variation were found on the other body parts. Measuring the size of a particular colour pattern, the intensity of colour expression (degree of melanization) and statistical analyses allowed an assessment of the intra-individual variation in both discrete and continuous patterns. The results revealed substantial modularity in the above mentioned colouration traits. In workers of $F$. rufa there were individuals with a dark head and light coloured thorax and vice a versa. Size of the dark pigment colour patterns exhibited less modularity than the degree of melanization. Finally, the interrelation between colouration traits and individual body size revealed their size-dependent origin. Small individuals had relatively larger areas of colour on the head and thorax than big individuals. These results are likely to facilitate further taxonomical and ecological studies on red wood ants, as they show it is possible to assess colouration traits in ants. However, more studies are needed on the function of polymorphism and modular colouration in this group of ants.
\end{abstract}

\section{INTRODUCTION}

Animals largely use pigment and structural colours for signalling, camouflage or mimicry, and various colouration traits assist in the physical protection, temperature regulation and physiology of organisms (Cott, 1940). Recently Pérez-Rodríguez et al. (2017) suggested that pigment colour patterns are indicators of individual quality, acting via at least four pathways: (a) as conventional signals of status; (b) as indices of developmental homeostasis; (c) as an amplifying cue of somatic integrity; (d) by amplifying individual investment in maintenance activities. Melanin pigments are responsible for the black and brown colours in the majority of arthropods (Fuzeau-Braesch, 1972), with the exception of spiders (Oxford \& Gillespie, 1998). In insects, melanin-based ornaments can accurately reveal individual quality because of the immunomodulatory and anti-oxidative action of the pigments (McGraw, 2005). However, this is species-specific (Stoehr, 2006), as species vary in the degree of genotype-by-environment interactions in colour pattern origin, and genetically pre- conditioned traits cost less to produce than condition-dependent traits. As, reviewed by Roulin (2016), melanization in invertebrates is generally less affected by genetic factors than in vertebrates, therefore melanin ornaments in insects may be more dependent on the environment than genetically determined. For many insects, melanin colouration is a significant indicator of an individual's quality: Nymphalidae (Talloen et al., 2004), Noctuidae (Lee et al., 2008), Coccinellidae (Bezzerides et al., 2007), Tenebrionidae (Kangassalo et al., 2016) and Coenagrionidae (Joop et al., 2006). Yet there is little information on melanin-based colouration of Formicidae (but see Williams et al., 1987; de Souza et al., 2011), and the colour of red wood ants in particular is still poorly studied.

Red wood ants belonging to the Formica rufa group are keystone species in the Northern Hemisphere. They inhabit boreal mixed and single-species coniferous forests, temperate broadleaved and mixed deciduous forests, forest edges and can occur in meadows. Being ecosystem engineers, wood ants influence carbon and nitrogen flows 
(Risch et al., 2005; Frouz et al., 2016), improve soil properties (Frouz \& Jílková, 2008) and affect concentrations of macroelements in tree roots and thus regulate their growth (Ohashi et al., 2007). These insects regulate structure and biodiversity of forest plants and animal communities, contributing to seed dispersal (Gorb et al., 2000) and provide suitable habitats for numerous other invertebrates (Härkönen \& Sorvari, 2014; Parmentier et al., 2014; Elo et al., 2016). Red wood ants, like other ants, provide various ecosystem services (Del Toro et al., 2012). Consequently, they have been extensively studied during the last four decades throughout their area of distribution in Europe, but much less so in North America (see Jurgensen et al., 2005; Stockan et al., 2016; Trager, 2016).

Due to rapid loss of suitable habitats, the European species of red wood ants, but not the North American species, appear to be among threatened species with a globally near threatened status according to the IUCN (IUCN, 2016). Thus, there are several studies on wood ant biomonitoring, conservation and management (Seppä, 2008; Dekoninck et al., 2010; Fedoseeva, 2011; Gilev, 2011; Sorvari, 2016). Body size, weight and pilosity are the most frequent parameters used in biomonitoring surveys. As reported by Fedoseeva (2011), asymmetry in the shape of the petiole can also provide information about long-term settlement degradation. Although colouration traits are effective and non-invasive indicators of environmental stress (Lifshitz \& St Clair, 2016), they are not widely used in studies on ants. To our knowledge, the only exception is the approach proposed by Gilev $(2002,2003)$ and by Gilev et al. (2015) and used by Korochkina et al. (2014). These authors use phenetics to describe the colouration of red wood ants in relation to population structure and possible historical reconstruction of the postglacial recolonization. In our previous study (Skaldina \& Sorvari, 2017) it was found that the colour of the heads of gynes of Formica aquilonia (Yarrow, 1955), in terms of the incidence of different colour morphs and increased degree of melanization, can indicate forest disturbance due to clearing. Therefore, red wood ant colouration could also be used for biomonitoring purposes. However, knowledge of natural variability in colouration of species from unmanaged habitats is needed in order to provide the necessary baseline for further research.

The role and significance of colouration traits differ between species, even closely related species (Stoehr, 2006). Therefore, in this study we focused on precise descriptions of the colouration of the workers of the red wood ant, Formica rufa (Linnaeus, 1761); in particular the morphs, shape and size of the dark melanized patterns and the degree of melanization of the head and thorax. Overall, the major goal of this study was to reveal the type and directions of the variability within-species colouration in the monogynous red wood ant $F$. rufa in unmanaged forests in southern Finland.

\section{MATERIALS AND METHODS}

\section{Study sample and study area}

In Finnish coniferous and mixed forests the F. rufa group comprises five species: Formica aquilonia (Yarrow, 1955), Formica lugubris (Zettersted, 1840), Formica polyctena (Forster, 1850), Formica pratensis (Retzius, 1783) and Formica rufa (Yarrow, 1955) all of which are ecological dominants in terrestrial ecosystems (Punttila \& Kilpeläinen, 2009). Although closely related, they have different life history strategies and social organisations (Rosengren et al., 1993). The Finnish red wood ant, F. rufa, is mainly monogynous and monodomous with the simplest type of social organisation (mainly one queen mating with one or several males). Therefore, this species is a good candidate for studying the importance of its colouration and how it might be used in biomonitoring. Workers are the most abundant caste in ants, performing various tasks for the family and spending much time inside and outside a nest, that is why they were the focus of this study. A total of 336 F. rufa individuals from 20 different colonies (Mean \pm SD: $16.8 \pm 4.2$ individuals per nest) were sampled in May 2012. Ants were manually collected from the top of the nest mound and stored in $96 \%$ ethanol. The nests studied were at the edges of forests in the surroundings of Turku $\left(60.42^{\circ}, 22.27^{\circ}\right)$ on the south-western coast of Finland. The size of each nest was measured in terms of the diameter at the base of the organic part of the nest mound. In the sample studied the diameter of F. rufa nests varied from 0.8 to $1.4 \mathrm{~m}$. The most distant nests were 10.2 kilometres apart and the closest $0.2 \mathrm{~km}$ apart. The nests typically occurred in separate forest stands/patches; in two cases the nests were in the same forest stand, but were separate colonies (monodomy). The dominant trees in the forests were Pinus sylvestris (Linnaeus, 1753), Picea abies ((L.) H. Karst, 1881) and Quercus robur (Linnaeus, 1753).

\section{Digital photography}

Digital photography was the initial step in the analysis of the variation in colour. The heads and thoraxes were photographed separately on a millimeter paper background and each photograph was given an individual code for future processing. All the photographs were taken using a digital stereo microscope Olympus SZ40 and DeltaPix Invenio 3S 3 Mpixel CMOS camera set at a magnification $\times 40$ for the head and $\times 25$ for the thorax, with a constant luminance of 2,800 lx. The photographs were further processed with Delta Pix Viewer LE, Adobe Photoshop CS5 and Image J software. For the analyses of the degree of melanization (MD) photographs were converted into greyscale.

\section{Morphometrics}

The maximum width of the head above the eyes (Sorvari \& Hakkarainen, 2009) and thorax length were used for estimating an ant's individual body size. In addition, clypeus width was measured as the maximum distance between left and right margins, and used in the calculation of the index of clypeal pigmentation. Use of index parameters facilitates studies of complex colouration traits (Dlussky et al., 1998). For the calculation of relative clypeus melanization we used an index of clypeus melanization (see colour pattern and melanization analyses). The measurements were done using ImageJ software, setting the scale to $1 \mathrm{~mm}$.

\section{Colour pattern and analysis of melanization}

In order to describe the variation in colour of F. rufa workers, we first made a qualitative analyses of the colour morphs, then conducted several quantitative measurements and finally analyzed the existing interrelations statistically. While conducting the visual categorization, we were guided by the population morphology approach, established for wood ants by Gilev (2002); however, a threshold approach (Roff, 1996) was used for precise categorization (Figs 2 and 3). In our study several aspects of the colour patterns were considered, as both the shapes of melaninbased colour morphs, the percentage of melanized area and the 


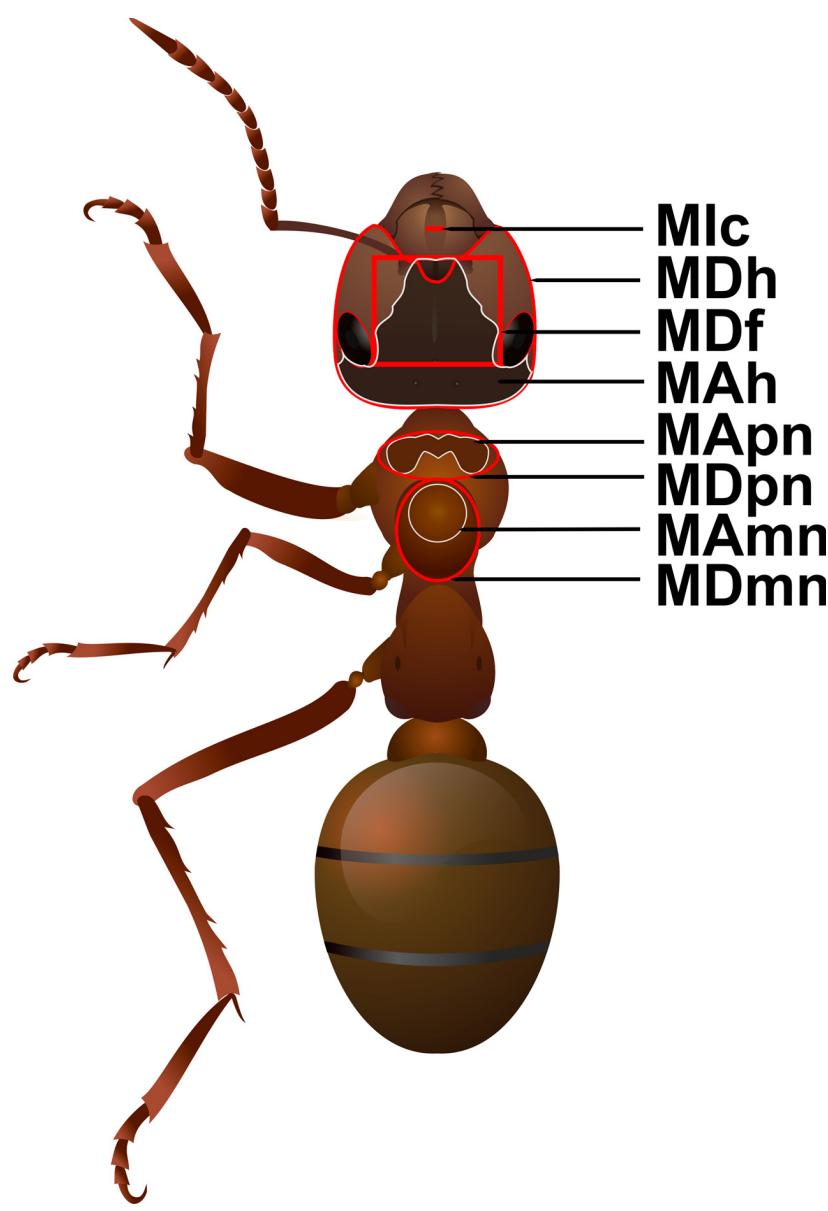

Fig. 1. Areas of the body of $F$. rufa used in the analyses of melanin-based colouration. Mlc - clypeus melanization index; MDh - degree of melanization of the whole head; MDf - degree of melanization of the standardized rectangular area on the frons of the head; MAh - area of melanization on the head; MApn - area of melanization on the pronotum; MDpn - degree of melanization of the pronotum; MAmn - area of melanization on the mesonotum; MDmn - degree of melanization of the mesonotum.

mean darkness were taken into account. Thus, a colour morph was categorized as discrete, when it had a symmetrical (left/right) and well recognisable shape that could be assessed visually. In those cases in which the variability in colour was not symmetrical or varied only in the size of the pigmented area we categorized it as continuous. The categorization analyses of the head colour morphs included 332 photographs of which 301 were of pronotum colour morphs. Several photographs of the total sample were excluded due to insufficient quality, mainly caused by mechanical damage during the head-thorax separation process. In addition, continuous variability of the clypeus was measured using an index for clypeus melaniszation (MIc). For the MIc the width of the vertical dark stripe in the central part of the clypeus was measured and then divided by clypeus length. For the analysis of cuticular melanization we studied the following parameters, proportion of the area melanized (MA), which shows how big the dark pattern is and the degree of melanization (MD), as a measure of the intensity of colour. The area melanized was calculated as the percentage of surface melanized $\left(\mathrm{mm}^{2}\right)$ in relation to the entire area of the head $\left(\mathrm{mm}^{2}\right)$, excluding the compound eyes, clypeus and mandibles on the $2 \mathrm{D}$ greyscale photographs. The MA on the pronotum and mesonotum was assessed as the ratio of the dark pattern on the visible surface in the $2 \mathrm{D}$ photographs. MD was measured in terms of the mean greyscale darkness of the pixels,

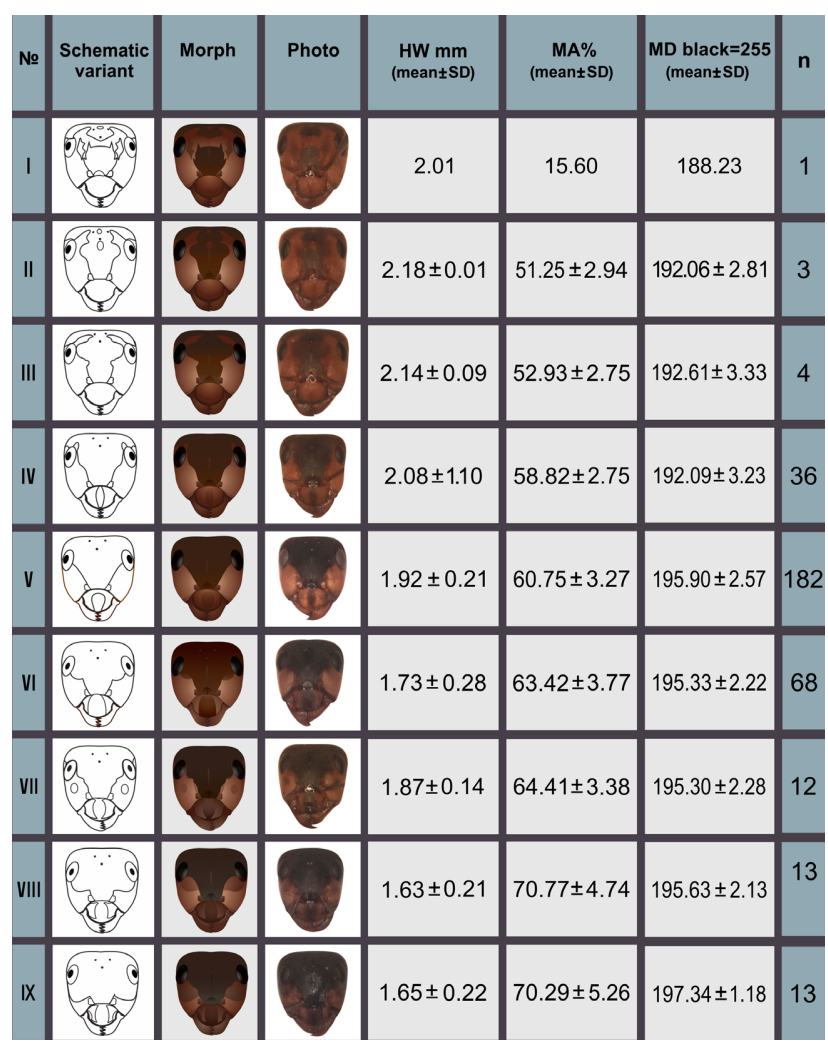

Fig. 2. Variation in the melanin-based colour morphs of the heads of $F$. rufa and their quantitative expression. Assessed parameters: head width (HW), area of melanization (MAh), degree of melanization (MDh) $(n=332)$. Each threshold rank corresponds to the same-numbered morph. I - black melanin pattern present on the frons as four disparate elements. II - melanin patterns merged, forming a central stripe with a hole(s) in the upper part. III - melanin patterns merged, forming central frons cross-like stripe without a hole. IV - the line of the border between the black and red parts of the face is concave above the compound eyes. V - the line of the border between black and red parts of the face is straight and touches the lower part of the compound eyes. $\mathrm{VI}$ - the line of the border between black and red parts of the face is convex and touches the lower part of the eyes. VII - the line of the border between black and red parts of the face is convex and touches the lower part of the eyes and there are pigmented spots on the cheeks. VIII - convexities on the cheeks are big and extend to the middle of the cheeks. IX - the edge of the convexities of the dark pigment touches the basement of the antennae.

calibrated on a scale of which 0 - was completely white, and 255 - completely dark black in ImageJ (Sorvari et al., 2008; Fedorka et al., 2013). MD of the following areas was measured: (1) the head (MDh); (2) pronotum (MDpn); (3) mesonotum (MDmn), and MD of MA (MAh) was also taken into account. In addition, we measured MD of a standardized area of the frons (MDf) to simplify the analyses and found it can be used instead of MDh (correlation between MDf and MDh: $\mathrm{r}=0.89, \mathrm{P}<0.0001$; Fig. 1). Therefore, we used MDf in subsequent analyses.

\section{Statistics}

We used SPSS 21 for the Pearson correlations and SAS 9.4 statistical software (SAS Institute Inc.) for linear mixed model analyses. Nest was used as a random factor in the linear mixed models and a Kenward-Roger calculation for determining the degrees of freedom. The Pearson correlations were used to assess the level of integration and modularity between the area of the pigmented colour pattern, index of clypeal pigmentation and degree of melanization. Linear mixed models were used in analyses 


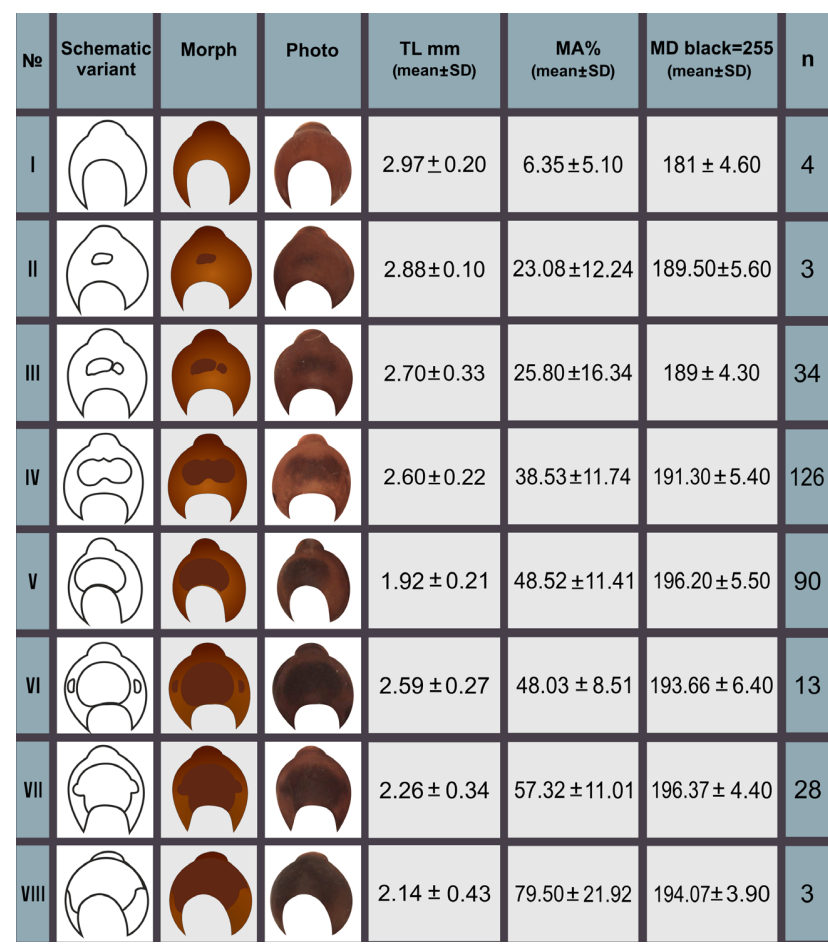

Fig. 3. Variation in the melanin-based colour morphs of the pronotum of $F$. rufa and their quantitative expression. Assessed parameters: thorax length (TL), area of melanization (MApn), degree of melanization (MDpn) $(n=301)$. Each threshold rank corresponds to the same-numbered morph. I - no dark pigmented patterns on the pronotum. II - single spot in the centre of pronotum. III - small elongated pattern on the pronotum. IV - big rounded pigmented pattern on the pronotum. $\mathrm{V}$ - rounded pigmented pattern, which touches the basal part of the pronotum. $\mathrm{VI}$ - rounded pigmented pattern, which touches the basal part of the pronotum and two lateral spots. VII - rounded pigmented pattern, touching the basal part of the pronotum and the lateral spots are merged with the central spot. VIII - big pigmented pattern, covering almost all of the pronotum.

of body and nest size related patterns in melanization. The data were normally distributed.

\section{RESULTS}

The categorization analyses of the variation in colour on the heads and pronotums of the workers revealed nine and eight discrete colour morphs, respectively (Figs 2 and 3; Appendix 1). On the other body parts, melanin-based patterns were more continuous with no distinct morphs but variable areas of pigmentation. Analyses of the combination frequencies of head-pronotum colour morphs revealed that the most common phenotypes of $F$. rufa in the area studied were the combinations $\mathrm{V}$ head and IV (26.16\%) and $\mathrm{V}$ pronotum $(18.06 \%)$ colour morphs (Table 1). Each of these colour morphs could be described using quantitative parameters, such as area of melanization (MA) and degree of melanization (MD), however, the colour morphs could not be totally substituted by them. MA and MD can be measured on the body parts with continuous colour variability. The existence of well recognisable differences in the colour on the heads and pronotums indicates that the colouration of F. rufa can be described as polymorphic.

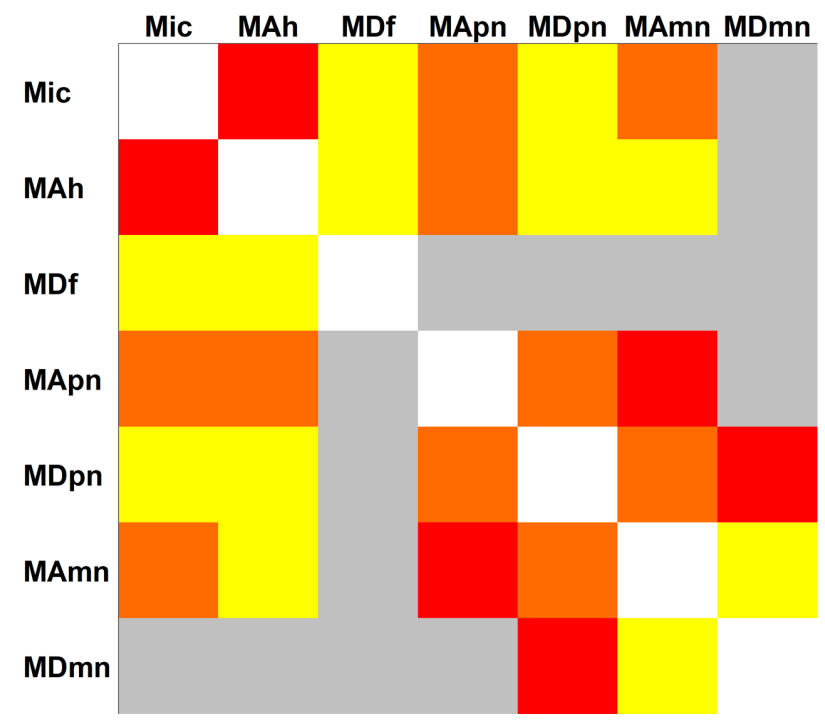

Fig. 4. Modularity of the colouration in the red wood ant $F$. rufa $(\mathrm{n}=$ 336). Different colours reflect Pearson correlation coefficients between the colour traits studied: red $(r>0.5)$, orange $(r=0.5-0.3)$, yellow ( $r=0.3-0.1)$, grey (correlation is not significant).

When the interconnection between the colour patterns on the different body parts was investigated, it was found that they were not always closely interrelated, as in many cases ants with dark coloured heads had lighter thoraxes and vice versa. Colour patterns on the head, such as the area of the dark pattern on the head (MAh) and clypeal pigmentation (MIc) were positively correlated with each other $(r=0.570$, $\mathrm{P}<0.0001)$. The relative size of the colour patterns on the thorax, MApn and MAmn, were also positively correlated $(\mathrm{r}=0.571, \mathrm{P}<0.0001)$. Interestingly, there were notably weaker positive correlations between the melanized areas on the head and pronotum $(\mathrm{r}=0.301, \mathrm{P}<0.0001)$ and head and mesonotum $(\mathrm{r}=0.205, \mathrm{P}<0.0001)$. On the other hand, MIc was also positively correlated with MApn and MAmn ( $\mathrm{r}=0.446, \mathrm{P}<0.0001 ; \mathrm{r}=0.464, \mathrm{P}<0.0001$; respectively). The degree of melanization of the frons (MDf) was not associated with MDpn $(\mathrm{r}=0.071, \mathrm{P}=0.268)$ and MDmn $(\mathrm{r}=0.099, \mathrm{P}=0.88)$, however MDpn and MDmn were highly correlated $(\mathrm{r}=0.67, \mathrm{P}<0.0001)$. These results may indicate that the colour traits of some body parts of $F$. rufa are more closely associated than others, i.e., they show a detectable level of modularity (Fig. 4). Parameters of the colour patterns such as the area and the degree of melanization can be different, as the relative sizes of the pigmented

Table 1. Frequencies of combinations in head (I-IX) and pronotum (I-VIII) colour morphs in the samples of the red wood ant, Formica rufa, studied $(\mathrm{n}=321)$.

\begin{tabular}{rrrrrrrrr}
\hline & I & II & III & IV & V & VI & VII & VIII \\
\hline II & 1 & & & & & & & \\
III & & 2 & 1 & & & & & \\
IV & & 2 & 15 & 17 & 1 & & & \\
V & 1 & 2 & 14 & 84 & 58 & 6 & 7 & 1 \\
VI & & & 2 & 28 & 21 & 3 & 10 & 2 \\
VII & & & & 5 & 2 & 3 & 2 & \\
VIII & & & & 2 & 7 & 1 & 4 & \\
IX & & & & & 8 & & 5 & \\
\hline
\end{tabular}



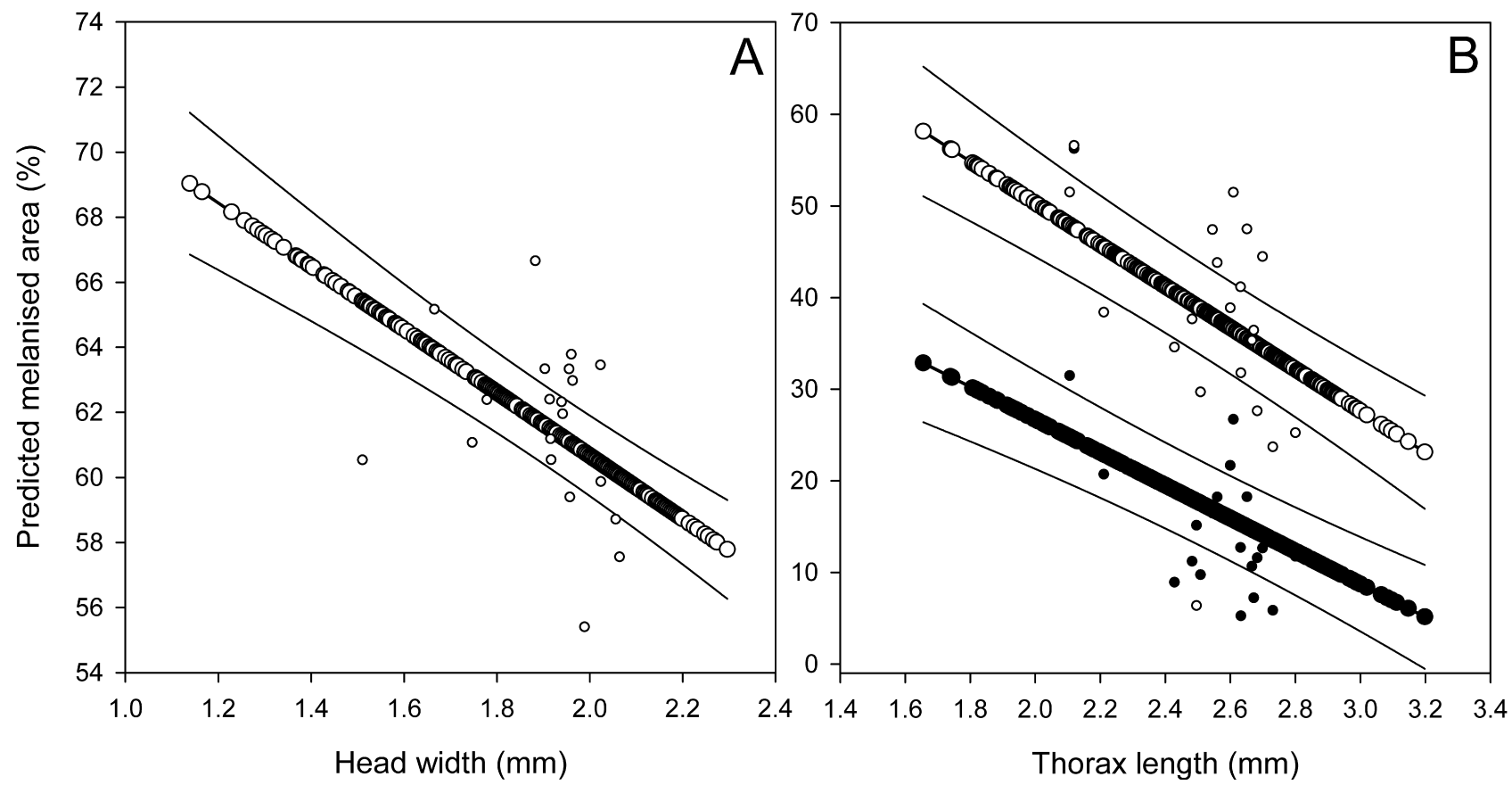

Fig. 5. Association between the area melanized and individual body size in the red wood ant Formica rufa. A - association between area of melanization on the head and head width; B - association between area of melanization on both the pronotum (open symbols) and mesonotum (filled symbols), and thorax length. The predicted line, with values and $95 \%$ confidence limits, of the mixed models are presented $(n=336)$. Small symbols are colony mean values from the raw data.

pattern on the clypeus, frons, pronotum and mesonotum is more consistent than the degree of melanization. For this reason, when studying the interrelations between colouration and size in an organism the area of pigmentation is a more informative than the degree of melanization.

Considering both polymorphism and modularity, it was found that the colour traits of $F$. rufa are size-dependent. With nest as a random factor, the linear mixed models revealed that an increase in head width is associated with a decrease in MAh $\left(\mathrm{F}_{1,327}=63.02, \mathrm{P}<0.0001\right)$ (Fig. 5A). Similarly, an increase the length of the thorax is associated with a decrease in both MApn $\left(\mathrm{F}_{1,244}=60.35, \mathrm{P}<0.0001\right)$ and MAmn $\left(\mathrm{F}_{1,295}=45.58, \mathrm{P}<0.0001\right)$ (Fig. 5B).

None of the colour traits studied, except MDmn, were associated with nest size: $\operatorname{MDf}\left(\mathrm{F}_{1,18.3}=0.72, \mathrm{P}=0.41\right)$, $\operatorname{MDpn}\left(\mathrm{F}_{1,18.7}=1.83, \mathrm{P}=0.19\right), \operatorname{MDmn}\left(\mathrm{F}_{1,19.6}=4.89, \mathrm{P}\right.$ $=0.04)$.

\section{DISCUSSION}

At the edges of Finnish forests, which had not recently been managed in any way, the patterns in the colour of $F$. rufa was both continuous and discrete, and defining the colour morphs using the threshold approach revealed two types of variation. The distribution of the frequencies of the different morphs revealed the presence of common and rare combinations, which may account for why some morphs were recorded only once or twice in the samples studied. The main processes driving the evolution of colour, are thought to be natural selection for signalling, camouflage or thermoregulation (Stuart-Fox \& Moussalli, 2009). Recently thermoregulation was proposed as one of the major driving factors of the evolution of dark colours in Polistes wasps (De Souza et al., 2017), which may also be the case for the red wood ant. However, this needs further research. We did not find any interrelationship between melanin colouration and nest size (except the degree of melanization of the mesonotum). In order to determine the ecological significance of colour polymorphism in red wood ants further studies are needed in which the samples are larger and are collected from different locations with a wider range of environmental conditions. The value of this study is that it describes the variation in colour polymorphism, which will facilitate future research at the level of a "whole organism" rather than a "single trait", as proposed by Forsman (2015) and in so doing reveal the influence of various selective pressures on the dimensions of a phenotype.

Melanin-based colouration of F. rufa is modular in its organization, as colour traits on the head and thorax are not strongly corelated. The concept of integration and modularity as established by Klingenberg (2008) can be applied to colouration. According to this concept, integration is higher when all sets of variation are directed and there is a strong correlation between measurements, however, only a weak interaction exists between modules. Modularity is simply the difference in the degree of integration within and between sets of traits; and "a module is a unit that is tightly integrated internally but relatively independent from other such modules" (Klingenberg, 2008). Subparts, forming one module, face the same selective pressure and may co-evolve semi-independently from subparts of other modules. Possessing these phenotypic building blocks, or modules, enables the development of phenotypes via developmental recombination (West-Eberhard, 2003; Londe et al., 2015). Applying the modularity concept has resulted in the precise description of abnormalities such as gynandromorphs in Pheidole (Hymenoptera: Formicidae) ants 
(Yang \& Abouheif, 2011) and might be useful for further revealing other signs of developmental instabilities. Modular colouration is described by Williams (2007) in bumblebees and by Perrard et al. (2014) in the yellow-legged hornet Vespa velutina (Lepeletier, 1836). Modular organisms may exhibit differentiated or restricted phenotypic responses, as various modules may have different response thresholds to the same inducing factor (Forsman, 2015). In terms of the colouration of the red wood ants this could mean that the head and thorax may exhibit different responses in terms of colour traits to the same environmental factor. However, this needs further study.

When studying colouration, it is always important to know whether it is sensitive to the other body parameters (Bezzerides et al., 2007). Our results revealed, that such colour traits as the size of the pigmented area on the head, pronotum and mesonotum of $F$. rufa are associated with an individual's body size, as smaller individuals have larger melanized areas. Knowledge of the size-dependence of red wood ant melanin-based colouration is not new, as Dlussky (1967) and Gilev $(2002,2003)$ report that small individuals are generally darker. The finding that small workers generally have larger areas of pigmentation on the head and pronotum may relate to other life-history traits of this species. Polymorphism in ant size is well known for many species (Stradling, 1978; Hölldobler \& Wilson, 1990; Kamhi et al., 2016). Generally, it is related to polyethism or division of labour, in which individuals of different sizes perform various tasks for the entire family. Red wood ants are moderately polymorphic, differ greatly in body size, but lack true subcastes. In this species, polyethism is age-related and in some cases is correlated with body size. Small and young workers are often brood nurses, the intermediate aged - perform various tasks inside the nest, and the oldest and biggest are foragers, food suppliers and nest defenders; however, they can rapidly switch between tasks when necessary (Domisch et al., 2016). Interestingly, small intranidal nurse workers exhibit the strongest aggressive behaviour against arthropod parasites and are able to defend brood better than the big workers (Parmentier et al., 2015). In this study we only sampled ants from the top of ant hills, so it is very likely the analyses did not include all the functional groups of workers. Therefore, future studies on the colour traits of red wood ants should aim to sample individuals belonging to all the functional groups or workers.

In insects, a black cuticle is associated with a strong immune response (Armitage \& Siva-Jothy, 2005; Lee et al., 2008) and specific features of melanin-based colour patterns, like the degree of disruption or "brokenness" in the paper wasp, Polistes dominula (Christ, 1791), provide information about the agonistic abilities of the bearer (Tibbetts \& Dale, 2004). An analysis of the relationships between a red wood ants' colouration, size, immunity and behavior would further our ecological understanding and possibly reveal the functional significance of colouration in this group. It is possible, there is a trade-off in the investment of resources in an individual in size or melanization, because melanins are costly to produce and require proteins
(Blois, 1978). Recently, it was discovered that at the level of assemblages ants with dark cuticles are larger than those with pale cuticles (Bishop et al., 2016). Finally, opposite trends in the colouration of communities and species and size may reflect different selection pressures and functional differences in colouration in each particular case. For biomonitoring purposes, the finding of size-dependence of the colouration of the workers of $F$. rufa collected from relatively undisturbed populations is important, as anthropogenic disturbance is often thought to adversely affect body size in insects (Sorvari \& Hakkarainen, 2009; Fedoseeva, 2011).

Overall, our results indicate that red wood ants are not stochastically or uniformly black and red, but their colouration is polymorphic, modular and size-dependent. Being abundant, ecologically important, quickly responsive and easy to collect, ants are a valuable component of any monitoring programme (Underwood \& Fisher, 2006). Environmental stress can affect the life-history traits of invertebrates, such as fecundity and metamorphosis, which can provide an early warning of potentially irreversible changes. Therefore, we consider red wood ant colouration as a promising tool for biomonitoring purposes. First, because producing both symmetrical morphs and highly melanised patterns is costly, any changes in the degree and direction of melanization can reflect physiological responses to environmental factors. Second, revealing changes or abnormalities in colour modules may indicate specific selection pressures. Furthermore, knowledge about the size-dependence of colour traits in red wood ants is useful for future ecological and systematic studies. However, there should be further studies on the relationship between melanin colouration and individual quality. Genetic and ecological studies on red wood ant colouration may reveal the cost of morph and melanin production in ants.

\section{CONCLUSIONS}

The colouration of red wood ants, F. rufa, collected from unmanaged habitats in Finland is polymorphic, modular and size-dependent. Both polymorphic ornamentation and melanin are costly to produce, thus colouration in red wood ants may signal an individual's quality. In future research on the ecology of the red wood ant it is worth considering the colouration of both the head and thorax, as colouration in this ant is modular in its organization. Melanin-based colouration in F. rufa is size-dependent, thus in red wood ants there might be a trade-off between investment in size and a heavily melanized cuticle. In future studies on colouration in ants it is always worth considering the speciesspecific manifestation of colour.

ACKNOWLEDGEMENTS. We are grateful to two anonymous reviewers, T. Eeva, B. Markó and S. Sumner for their valuable comments, which significantly improved the quality of this paper. We kindly thank N. Buzhenina for assistance with the artwork for the figures. We also thank D. Blande for his comments on the content and language of the manuscript. L. Piqué made blind assessment of head and pronotum colour morphs and provided comments on how to improve the methodology. This study was financially sup- 
ported by grants from Centre for International Mobility CIMO, Kuopio Naturalists Society and the University of Eastern Finland to OS.

\section{REFERENCES}

Armitage S.A.O. \& Siva-Jothy M.T. 2005: Immune function responds to selection for cuticular colour in Tenebrio molitor. Heredity 94: 650-656.

Bezzerides A.L., McGraw K.J., Parker R.S. \& Husseini J. 2007: Elytra color as a signal of chemical defense in the Asian ladybird beetle Harmonia axyridis. - Behav. Ecol. Sociobiol. 61: 1401-1408.

Bishop T.R., Robertson M.P., Gibb H., van Rensburg B.J., Braschler B., Chown S.L., Foord S.H., Munyai T.C., OKey I., Tshivhandekano P.G., Werenkraut V. \& Parr C.L. 2016: Ant assemblages have darker and larger members in cold environments. - Glob. Ecol. Biogeogr. 25: 1498-1499.

BLoIs M.S. 1978: The melanins: their synthesis and structure. In Smith K.C. (ed.): Photochemical and Photobiological Reviews. Springer, Plenum Press, New York, pp. 115-134.

Cотт H.B. 1940: Adaptive Colouration in Animals. Oxford University Press, Methuen, 602 pp.

DE Souza D.J., Devers S. \& LenoIr A. 2011: Blochmannia endosymbionts and their host, the ant Camponotus fellah: cuticular hydrocarbons and melanization. - C. R. Biol. 334: 737-741.

de Souza A.R., Turillazzi S., Lino-Neto J. \& Santini G. 2017: Colder environments may select for darker paper wasps. Biol. J. Linn. Soc. 120: 700-704.

Dekoninck W., Hendrickx F., Grootaert P. \& Maelfait J.-P. 2010: Present conservation status of red wood ants in northwestern Belgium: worse than previously, but not a lost cause. - Eur. J. Entomol. 107: 209-218.

Del Toro I., Ribbons R.R. \& Pelini S.L. 2012: The little things run the world revisited: a review of ant-mediated ecosystem services and disservices (Hymenoptera: Formicidae). - Myrmycol. News 17: 133-146.

DLussky G.M. 1967: Ants of the Genus Formica. Nauka, Moscow, 236 pp. [in Russian].

Dlussky G.M., Fedoseeva E.B. \& Thompson L.C. 1998: Variability of the ants Solenopsis richteri and $S$. wagneri (Hymenoptera, Formicidae): statistical analyses of morphometric characters. - Biol. Bull. Rev. 118: 283-298 [in Russian].

Domisch T., Risch A.C. \& Robinson E.J.H. 2016: Wood ant foraging and mutualism with aphids. In Stockan J.A. \& Robinson E.J.H. (eds): Wood ant Ecology and Conservation. Cambridge University Press, Cambridge, pp. 145-176.

Elo R.A., Penttinen R. \& Sorvari J. 2016: A comparative study of oribatid mite communities in red wood ant Formica polycte$n a$ nests and surrounding soil in a Finnish oak forest. - Insect Conserv. Diver. 9: 210-223.

Fedorka K.M., Lee V. \& Winterhalter W.E. 2013: Thermal environment shapes cuticle melanism and melanin-based immunity in the ground cricket Allonemobius socius. - Evol. Ecol. 27: 521-531.

Fedoseeva E.B. 2011: Morphometric characteristics of Formica aquilonia ants in monitoring of their settlements. - Entomol. Rev. 91: 152-168.

Forsman A. 2015: Rethinking phenotypic plasticity and its consequences for individuals, populations and species. - Heredity 115: $276-284$.

Frouz J. \& Jílková V. 2008: The effect of ants on soil properties and processes (Hymenoptera: Formicidae). - Myrmecol. News 11: 191-199.
Frouz J., Jílková V. \& Sorvari J. 2016: Contribution of wood ants to nutrient cycling and ecosystem function. In Stockan J.A. \& Robinson E.J.H. (eds): Wood Ant Ecology and Conservation. Cambridge University Press, Cambridge, pp. 207-220.

Fuzeau-Braesch S. 1972: Pigments and color changes. - Annu. Rev. Entomol. 17: 403-424.

GiLev A.V. 2002: Discrete variations of coloration and some patterns of pigmentation variability in workers of wood ants of the subgenus Formica (Hymenoptera, Formicidae). - Entomol. Rev. 82: 481-486 [in Russian].

GiLev A.V. 2003: The population pattern of the ant Formica aquilonia (Hymenoptera, Formicidae) in the Middle Urals. - Biol. Bull. Rev. 123: 223-228 [in Russian].

GiLev A.V. 2011: Spatial distribution of red wood ants and scientific basis of their protection. - Entomol. Rev. 91: 133-140.

Gilev A.V., Mershchiev A.V. \& Malyshev D.S. 2015: Interpretation of postglacial recolonization of Formica aquilonia (Hymenoptera, Formicidae) in Fennoscandia according to workers' color variation. - Entomol. Rev. 95: 941-946.

Gorb S.N., Gorb E.V. \& Punttila P. 2000: Effects of redispersal of seeds by ants on the vegetation pattern in a deciduous forest: a case study. - Acta Oecol. 21: 293-301.

HÄRKÖNEN S.K. \& SORVARI J. 2014: Species richness of associates of ants in the nests of red wood ant Formica polyctena (Hymenoptera, Formicidae). - Insect Conserv. Diver. 7: 485-495.

Hölldobler B. \& Wilson E.O. 1990: The Ants. The Belknap Press of Harvard University Press, Cambridge, MA, 733 pp.

IUCN 2016: The IUCN Red List of Threatened Species. Ver. 2016-2. URL: http://www.iucnredlist.org.

Joop G., MitschKe A., Rolff J. \& SivA-Jothy M.T. 2006: Immune function and parasite resistance in male and polymorphic female Coenagrion puella. - BMC Evol. Biol. 6: 19, 10 pp.

Jurgensen M.F., Storer A.J. \& Risch A.C. 2005: Red wood ants in North America. - Ann. Zool. Fenn. 42: 235-242.

Kamhi J.F., Nunn K., Robson S.K.A. \& Traniello J.F.A. 2015: Polymorphism and division of labor in a socially complex ant: neuromodulation of aggression in the Australian weaver ant Oecophylla smaragdina. - Proc. R. Soc. Lond. (B) 282: 20150704, 9 pp.

Kangassalo K., Kosonen K., Pölkki M., Sorvari J., Krams I. \& RANTALA M.J. 2016: Immune challenge has a negative effect on cuticular darkness in the mealworm beetle, Tenebrio molitor. - Ann. Zool. Fenn. 53: 255-262.

KLINGENBERG C.P. 2008: Morphological integration and developmental modularity. - Annu. Rev. Ecol. Evol. Syst. 39: 115-132.

Korochina N.I., Konopleva E.E. \& Zryanina T.A. 2014: Population structure of Formica aquilonia (Hymenoptera, Formicidae) at the boundary of boreal and subboreal landscapes in the Volga river region. - Entomol. Rev. 94: 664-674.

LeE K.P., Simpson S.J. \& WiLson K. 2008: Dietary protein-quality influences melanisation and immune function in an insect. Funct. Ecol. 22: 1052-1061.

Lifshitz N. \& St Clair C.C. 2016: Coloured ornamental traits could be effective and non-invasive indicators of pollution exposure for wildlife. - Conserv. Physiol. 4: 1-16.

Londe S., Monnin T., Cornette R., Debat V., Fisher B.L. \& Molet M. 2015: Phenotypic plasticity and modularity allow for the production of novel mosaic phenotypes in ants. EvoDevo 6: $36,15 \mathrm{pp}$.

McGraw K.J. 2005: The antioxidant function of many animal pigments: are there consistent health benefits of sexually selected colourants? - Anim. Behav. 69: 757-764.

Ohashi M., Kilpeläinen J., Finer L., Risch A.C., Domisch T., Neuvonen S. \& Niemelä P. 2007: The effect of red wood ant (Formica rufa group) mounds on root biomass, density and nu- 
trient concentrations in boreal managed forests. $-J$. For. Res. 12: $113-119$.

OXford G.S. \& Gillespie R.G. 1998: Evolution and ecology of spider coloration. - Annu. Rev. Entomol. 43: 619-643.

Parmentier T., Dekoninck W. \& Wenseleers T. 2014: A highly diverse microcosm in a hostile world: a review on the associates of red wood ants (Formica rufa group). - Insectes Soc. 61: 229-237.

Parmentier T., Dekoninck W. \& Wenseleers T. 2015: Contextdependent specialization in colony defense in the red wood ant Formica rufa. - Anim. Behav. 103: 161-167.

Pérez-Rodríguez L., Jovani R. \& Stevens M. 2017: Shape matters: animal colour pattern as signals of individual quality. Proc. R. Soc. Lond. (B) 282: 20162446, 10 pp.

Perrard A., Arca M., Rome Q., Muller F., Tan J., Bista S., Nugroho H., Baudoin R., Baylac M., Silvain J.F., Carpenter J.M. \& Villemant C. 2014: Geographic variations of melanisation patterns in a hornet species: genetic differences, climatic pressures or aposematic constraints. - PLoS ONE 9(4): e94162, $16 \mathrm{pp}$.

PuntTILA P. \& KilpeläINEN J. 2009: Distribution of mound-building ant species (Formica spp., Hymenoptera) in Finland: preliminary results of a national survey. - Ann. Zool. Fenn. 46: $1-15$.

Risch A.C., Jurgensen M.F., Schütz M. \& Page-Dumroese D.S. 2005: The contribution of red wood ants to soil $\mathrm{C}$ and $\mathrm{N}$ pools and $\mathrm{CO}_{2}$ emissions in subalpine forests. - Ecology 86: 419430.

RofF D.A. 1996: The evolution of threshold traits in animals. Q. Rev. Biol. 71: 3-35.

Rosengren R., Sundström L. \& Fortelius W. 1993: Monogyny and polygyny in Formica ants: the result of alternative dispersal tactics. In Keller L. (ed.): Queen Number and Sociality in Insects. Oxford University Press, Oxford, pp. 308-333.

Roulin A. 2016: Condition-dependence, pleiotropy and the handicap principle of sexual selection in melanin-based colouration. - Biol. Rev. 91: 328-348.

SEPPÄ P. 2008: Do ants (Hymenoptera: Formicidae) need conservation and does ant conservation need genetics? - Myrmecol. News 11: 161-172.

Skaldina O. \& SoRVARI J. 2017: Red wood ant colouration as an ecological indicator for the level of disturbance in managed coniferous forests. - Ecol. Indic. 72: 444-451.

SoRVARI J. 2016: Threats, conservation and management. In Stockan J.A. \& Robinson E.J.H. (eds): Wood Ant Ecology and Conservation. Cambridge University Press, Cambridge, pp. 264-286.

Sorvari J. \& HaKkarainen H. 2009: Forest clear-cutting causes small workers in the polydomous wood ant Formica aquilonia. - Ann. Zool. Fenn. 46: 431-438.

Stockan J.A., Robinson E.J.H., Trager J.C., Yao I. \& Seifert B. 2016: Introducing wood ants: evolution, phylogeny, identification and distribution. In Stockan J.A. \& Robinson E.J.H. (eds): Wood Ant Ecology and Conservation. Cambridge University Press, Cambridge, pp. 1-36.

Stoenr A.M. 2006: Costly melanin ornaments: the importance of taxon? - Funct. Ecol. 20: 276-281.

STRADLING D.J. 1978: The influence of size on foraging in the ant, Atta cephalotes, and the effect of some plant defense mechanisms. - J. Anim. Ecol. 47: 173-188.

Stuart-Fox D. \& Moussalli A. 2009: Camouflage, communication and thermoregulation: lessons from colour changing organisms. - Philos. Trans. R. Soc. 364: 463-470.
Talloen W., Van Dyck H. \& Lens L. 2004: The cost of melanization: butterfly wing coloration under environmental stress. Evolution 58: 360-366.

TibBetts E.A. \& DALE J. 2004: A socially enforced signal of quality in a paper wasp. - Nature 432: 218-222.

Trager J.C. 2016: Diversity, ecology and conservation of wood ants in North America. In Stockan J.A. \& Robinson E.J.H. (eds): Wood Ant Ecology and Conservation. Cambridge University Press, Cambridge, pp. 221-237.

UNDERWOOd E.C. \& FisheR B.L. 2006: The role of ants in conservation monitoring: If, when and how. - Biol. Conserv. 132: $166-182$.

West-Eberhard M.J. 2003: Developmental Plasticity and Evolution. Oxford University Press, New York, 794 pp.

WiLliams P.H. 2007: The distribution of bumblebee colour patterns world-wide: possible significance for thermoregulation, crypsis and warning mimicry. - Biol. J. Linn. Soc. 92: 97-118.

Williams D.F., Vander MeER R.K. \& Logfren C.S. 1987: Diet-induced nonmelanized cuticle in workers of the imported fire ant Solenopsis invicta Buren. - Arch. Insect Biochem. Physiol. 4: 251-259.

YANG A.S. \& ABouheIF E. 2011: Gynandromorphs as indicators of modularity and evolvability in ants. - J. Exp. Zool. (B) 316: 313-318.

Received December 15, 2016; revised and accepted June 5, 2017 Published online June 19, 2017

Appendix 1. The number of the head and pronotum colour morphs in the nests of the red wood ant, Formica rufa, studied.

\begin{tabular}{|c|c|c|c|c|c|c|c|c|c|}
\hline & \multicolumn{9}{|c|}{ Head colour morphs } \\
\hline Nest & I & II & III & IV & $\mathrm{V}$ & & VII & VIII & IX \\
\hline 1 & & & & 1 & 14 & & & 1 & \\
\hline 2 & & & & 1 & 14 & & 1 & 1 & \\
\hline 3 & & & & 4 & 10 & & & 2 & \\
\hline 4 & & & & & 17 & 1 & & & \\
\hline 5 & & & & 2 & 13 & & & & \\
\hline 6 & & & 1 & 10 & 6 & & & & \\
\hline 7 & & & & & 7 & & & 1 & 2 \\
\hline 8 & & & & 2 & 9 & & & 1 & 1 \\
\hline 9 & & & & & 4 & & & & \\
\hline 10 & & & & 2 & 10 & & & & \\
\hline 11 & & & & 7 & 6 & & & & \\
\hline 12 & & & & & 8 & & & & \\
\hline 13 & & & & & 2 & & 8 & 1 & \\
\hline 14 & 1 & 3 & 2 & 1 & 4 & & & 3 & \\
\hline 15 & & & & 1 & 10 & & & 1 & \\
\hline 16 & & & & 1 & 18 & & & & 2 \\
\hline 17 & & & & & 7 & & & 1 & \\
\hline 18 & & & & 2 & 10 & & & & \\
\hline 19 & & & & 1 & 9 & & & 1 & 2 \\
\hline \multirow[t]{2}{*}{20} & & & & & 4 & & 2 & 1 & 6 \\
\hline & \multicolumn{9}{|c|}{ Pronotum colour morphs } \\
\hline Nest & I & II & III & IV & & $\mathrm{V}$ & $\mathrm{VI}$ & VII & VIII \\
\hline 1 & & & & 8 & & 8 & 1 & & \\
\hline 2 & & 3 & 6 & 5 & & 2 & & & \\
\hline 3 & & & & 9 & & 7 & 1 & 5 & 1 \\
\hline 4 & & & 1 & & & 18 & & 5 & 2 \\
\hline 5 & & & 3 & 9 & & 6 & & & \\
\hline 6 & & & 7 & 10 & & & & & \\
\hline 7 & & & & 1 & & 1 & 2 & 8 & \\
\hline 8 & & & & 6 & & 7 & & & \\
\hline 9 & & & & 7 & & 3 & & 1 & \\
\hline 10 & & & & 7 & & 2 & & & \\
\hline 11 & & & 6 & 7 & & 1 & & & \\
\hline 12 & & & & 7 & & 1 & & & \\
\hline 13 & & & & 6 & & 2 & 3 & 1 & \\
\hline 14 & 3 & & 5 & 4 & & 2 & & & \\
\hline 15 & & & & 12 & & 3 & & & \\
\hline 16 & & & 2 & 9 & & 11 & & & \\
\hline 17 & & & 2 & 10 & & & 1 & 1 & \\
\hline 18 & & & 2 & 13 & & 3 & & & \\
\hline 19 & & & & 5 & & 12 & 1 & 1 & \\
\hline 20 & & & & & & 7 & 4 & 4 & \\
\hline
\end{tabular}

